\title{
The value of a psychiatric service within the venereal disease clinic
}

\author{
S. BHANJI* AND J. D. H. MAHONY† \\ From the *University of Exeter Postgraduate Medical Institute and the $†$ Alexanda Clinic, \\ St Giles Hospital, London
}

SUMmARY A significant proportion of attenders at venereal diseases clinics can be regarded as potential psychiatric patients. However, there have been few reports on the value of readily available psychiatric advice at such clinics. The findings during a three-month period when a psychiatrist attended a venereal disease clinic are described. Twenty-two patients were referred for psychiatric assessment. Of the 20 who kept their appointment, 18 were diagnosed as mentally ill or as having a personality disorder. Of these two were already under psychiatric care, but 11 had never previously sought psychiatric assistance. The major sources of common venereological and psychiatric concern appeared to be among the promiscuous and the hypochondriacal patients. The former consisted of persons with personality disorders who were thought unlikely to respond to psychiatric treatment; but some of the latter improved after treatment with pimozide. Some patients defaulted and not all who persevered were helped. Nevertheless the results of a questionnaire showed that the staff considered there was an important place for a psychiatrist within their clinic.

\section{Introduction}

Several authors have reported marked psychiatric morbidity and psychosocial distress among patients attending clinics for sexually transmitted diseases. As yet, few clinics have a psychiatrist in regular attendance. We recently carried out a study to determine whether there was a useful role for a psychiatrist in a clinic and to delineate common areas of concern.

\section{Materials and method}

The Alexanda Clinic serves an area in south-east London in which about $90 \%$ of the population belong to social classes III, IV, and V, and $10 \%$ are from overseas, mainly the West Indies. The clinic is staffed by four doctors, six nurses, and two social health workers (SHWs). During the three months beginning March 1977 a psychiatrist (SB) attended twice weekly to assess and, if possible, treat any patient whom any member of the clinic staff considered was psychologically disturbed. The views of the clinic staff were ascertained by a questionnaire at the end of the study.

Address for reprints: S. Bhanji, University of Exeter, Postgraduate Medical Institute, Barrack Road, Exeter EX2 5DW

Received for publication 30 November 1977

\section{Results}

During the period of the study 368 male patients and 358 female patients attended with new episodes of infection. Most had genital infections other than syphilis or gonorrhoea, but approximately $20 \%$ had no evidence of genital infection. Fifteen men and seven women were referred for a psychiatric opinion. The primary reasons for referral could be divided into four categories (Table 1): promiscuity associated with psychological disorder (Group 1), psychogenic physical complaints which were not relieved after reassurance (Group 2), psychogenic sexual dysfunction (Group 3), and pathological depression (Group 4).

The 20 patients who kept their appointments are shown in Table 1 according to the primary reason for referral. Their venereological diagnoses are shown in Table 2. Four patients had never contracted venereal disease, but eight had been infected at least twice. Two of the patients (Cases 8 and 19) were already receiving psychiatric treatment elsewhere, and five had previously seen psychiatrists but not necessarily for their current problems.

Table 1 shows that the presence of psychiatric or psychological disorder was confirmed in all but two patients and that the primary psychiatric conditions were personality disorder (five patients), depressive 
Table 1 Patients seen by psychiatrist

\begin{tabular}{|c|c|c|c|c|c|}
\hline Case No. & Sex & Age & Origin & Diagnosis & Times seen \\
\hline \multicolumn{6}{|c|}{ Group 1: Promiscuity } \\
\hline $1^{*}$ & $\mathbf{M}$ & 40 & UK & Personality disorder, homosexuality & 1 \\
\hline $2^{*}$ & $\mathbf{M}$ & 28 & UK & Personality disorder & 1 \\
\hline $3 *$ & $\mathbf{M}$ & 22 & West Indies & Personality disorder & 1 \\
\hline 4 & $\mathbf{M}$ & 33 & UK & Personality disorder, homosexuality, depression & 1 \\
\hline 5 & $\mathbf{F}$ & 17 & $\mathrm{UK} \dagger$ & Adolescent behaviour disorder & 2 \\
\hline $6^{*}$ & $\mathbf{F}$ & 20 & UK & No psychiatric disorder & 1 \\
\hline \multicolumn{6}{|c|}{ Group 2: Psychogenic complaints referable to somatic disorder } \\
\hline $7^{*}$ & $\mathbf{M}$ & 21 & Iran & Depression with hypochondriasis (venereophobia) & 1 \\
\hline 8 & $\mathbf{F}$ & 46 & Eire & Depression with hypochondriasis (venereophobia) & 1 \\
\hline 9* & $\mathbf{M}$ & 39 & Nigeria & Primary hypochondriasis (venereophobia) & 5 \\
\hline $10^{*}$ & $\mathbf{M}$ & 31 & UK & Primary hypochondriasis (venereophobia) & 2 \\
\hline 11 & $\mathbf{F}$ & 20 & UK & Obsessional neurosis with hypochondriasis (venereophobia) & 3 \\
\hline $12^{*}$ & $\mathbf{M}$ & 38 & Nigeria & Primary hypochondriasis (venereophobia) & 4 \\
\hline 13 & $\mathbf{M}$ & 22 & West Indies & Primary hypochondriasis (dermatozoiasis) & 4 \\
\hline \multicolumn{6}{|c|}{ Group 3: Psychogenic sexual dysfunction } \\
\hline $14^{*}$ & $\mathbf{M}$ & 27 & West Indies & Psychogenic impotence & 2 \\
\hline $15^{*}$ & $\mathbf{M}$ & 29 & UK & Psychogenic loss of libido & 1 \\
\hline $16^{*}$ & $\mathbf{M}$ & 38 & West Indies & No dysfunction & 1 \\
\hline \multicolumn{6}{|c|}{ Group 4: Depression } \\
\hline 17 & $\mathbf{M}$ & 66 & Poland & Depression & 1 \\
\hline $18^{*}$ & $\mathbf{F}$ & 56 & Eire & Depression (grief reaction) & 1 \\
\hline 19 & $\mathrm{~F}$ & 32 & UK & Personality disorder, mixed neurotic state & 1 \\
\hline $20^{*}$ & $\mathbf{M}$ & 38 & Holland & Depression & 2 \\
\hline
\end{tabular}

*Patients with no previous psychiatric contact

+Of West Indian parentage

Table 2 Venereological diagnoses at time of psychiatric assessment

\begin{tabular}{ll}
\hline Diagnosis & Case No. \\
Syphilis & 4 \\
Gonorrhoea & $1,2,3,5,16,19$ \\
Other genital infections & $6,14,15,18,20$ \\
No genital infection & $7,8,9,10,11,12,13,17$ \\
\hline
\end{tabular}

illness (5), primary hypochondriasis (4), psychogenic sexual dysfunction (2), obsessional neurosis (1), and adolescent behaviour disorder (1). Primary hypochondriasis was diagnosed if the patient's conviction of illness appeared to be circumscribed and not derived from underlying mental illness.

The extent of social problems can be assessed from the finding that three of the 10 patients who had married were divorced or separated, 10 were unemployed, three drank heavily (although without signs of physical dependency on alcohol), and three admitted to involvement with the police. All those referred because of promiscuity were venereological recidivists, as were four of the five with personality disorders. There were no racial differences in venereological diagnosis, in reason for referral, or in psychiatric diagnosis.

Of the 12 patients who were seen only once two had no evidence of psychiatric illness, four were thought unlikely to benefit from treatment (Cases 1, 3,4 , and 17), two were already under psychiatric care (Cases 8 and 19), one had gone abroad (Case 7), and three declined treatment (Cases 2, 15, and
18). Of the patients who accepted treatment five had not previously sought psychiatric advice.

The outcome of treatment varied. One patient (Case 20) was referred elsewhere, and one (Case 5), whose condition had improved with treatment, was advised to see the SHW for further counselling. The patients with hypochondriacal complaints were prescribed pimozide (Riding and Munro, 1975). The condition of three patients (Cases 9, 10, and 11) improved. The male patient with impotence was advised to attend with his wife but failed to do so. Finally, two of those seen only once (Cases 2 and 4) telephoned to report improvement.

At the end of the study a questionnaire was completed anonymously by the clinic staff. Ten reported an involvement in referring patients, and seven stated that this was helpful. Ten of the staff considered that regular psychiatric attendance in the future would be desirable.

\section{Discussion}

Surveys carried out using standardised screening procedures have shown much psychological abnormality among patients with venereal disease (Wells, 1970; Mayou, 1975). Mayou (1975) found that $20 \%$ of patients could be regarded as potential psychiatric cases, and Pedder and Goldberg (1970) reported an even higher prevalence. Most investigations of individual psychopathology have been confined to patients presenting with certain symptoms, such as syphilophobia (MacAlpine, 1957) and 
fear of venereal disease (Kite and Grimble, 1963), or with deviant or unconventional life-styles-for example male clients of prostitutes (Gibbens and Silberman, 1960), homosexuals (Fluker, 1966), and drug addicts (Linken, 1968). A recent exception is the report by Pedder (1970) of 40 unselected psychiatric patients referred during a 16-month period. The patients represented only $0.3 \%$ of the total new attendances.

Our patients compared with those of Pedder (1970) regarding sex and age distribution, marital state, and venereological diagnosis, but more of them were born outside the United Kingdom. There were more patients with hypochondriacal complaints in our study, but there were relatively fewer with personality disorders. In both studies several patients were seen on only one occasion, and a significant proportion of those offered treatment defaulted. Pedder (1970) did not state how many of his patients were already under psychiatric care, but he gives this as a reason for some being seen only once.

Most of the clinic staff welcomed the prospect of having readily available psychiatric expertise. At the end of the study this attitude had not altered overall. This is perhaps surprising as few patients showed any evidence of having been helped. However, it is possible that the benefit of easy access to psychiatric advice outweighed the disappointing outcome in certain instances.

The main areas of common venereological and psychiatric concern among the patients were promiscuity and hypochondriasis. Unfortunately the promiscuous group consisted largely of patients who were considered unlikely to benefit from psychiatric treatment. Venereophobia was the commonest of the hypochondriacal complaints. Controversy exists, as with hypochondriasis in general (Kenyon, 1976), over whether venereophobia occurs solely as a symptom of underlying mental illness or whether it can exist as an independent entity. MacAlpine (1957) regarded syphilophobia as a psychiatric symptom which could accompany or precede all stages of mental illness. Similarly, Kite and Grimble (1963) and Mayou (1975) found that venereophobia was associated with a variety of different psychiatric syndromes. Pedder (1970), by contrast, described three patients who showed no evidence of underlying psychiatric disorder. Our data likewise suggest that venereophobia can present in isolation. The use of pimozide in this condition merits further study. Finally, it appears that a small but significant number of patients with psychosexual dysfunction may present to the venereologist.

In conclusion, our experience accords with the view that a number of patients attending clinics for venereal diseases show sufficient psychopathology to justify specialist assessment. Furthermore, in some instances the psychological and genital symptoms appear to be interrelated. This finding, together with the fact that most of our psychologically disturbed patients were not under psychiatric care, suggests that there is an important place for the psychiatrist within the venereology clinic. However, not all the patients referred were willing to accept psychiatric help, and of those who were not all benefited.

This work was carried out while one of us (SB) was Honorary Senior Registrar to the Academic Department of Psychological Medicine, King's College Hospital, London SE5 9RS. Our thanks are owed to Professor R. H. Cawley for his encouragement and comments during the preparation of this paper. The demographic data on the Alexanda Clinic's catchment area were kindly provided by the MRC Social Psychiatry Unit, Institute of Psychiatry, London SE5 8AF.

\section{References}

Fluker, J. L. (1966). Recent trends in homosexuality in west London. British Journal of Venereal Diseases, 42, 48-49.

Gibbens, T. C. N., and Silberman, M. (1960). The clients of prostitutes. British Journal of Venereal Diseases, 36, 113-117.

Kenyon, F. E. (1976). Hypochondriacal states. British Journal of Psychiatry, 129, 1-14.

Kite, E. de C., and Grimble, A. (1963). Psychiatric aspects of venereal disease. British Journal of Venereal Diseases, 39, 173-180.

Linken, A. (1968). A study of drug-taking among young patients attending a clinic for venereal diseases. British Journal of Venereal Diseases, 44, 337-341.

MacAlpine, I. (1957). Syphilophobia. British Journal of Venereal Diseases, 33, 92-99.

Mayou, R. (1975). Psychological morbidity in a clinic for sexuallytransmitted disease. British Journal of Venereal Diseases, 51, 57-60.

Pedder, J. R. (1970). Psychiatric referral of patients in a venereal diseases clinic. British Journal of Venereal Diseases, 46, 54-57.

Pedder, J. R., and Goldberg, D. P. (1970). A survey by questionnaire of psychiatric disturbance in patients attending a venereal diseases clinic. British Journal of Venereal Diseases, 46, 58-61.

Riding, J., and Munro, A. (1975). Pimozide in the treatment of monosymptomatic hypochondriacal psychosis. Acta psychiatrica Scandinavica, 52, 23-30.

Wells, B. W. P. (1970). Personality study of VD patients: Using the psychoticism, extroversion, neuroticism inventory. British Journal of Venereal Diseases, 46, 498-501. 